\title{
Clinical significance of ultrasonic placental grading during third trimester in hypertensive disorders in pregnancy and its correlation with fetal outcome in tertiary care centre
}

\author{
Aruna Naik*, Susheela Khoiwal, Nisha Sharma, Priya Aarthy
}

Department of Obstetrics and Gynaecology, RNT Medical College, Udaipur, Rajasthan, India

Received: 12 August 2021

Accepted: 25 August 2021

\section{*Correspondence:}

Dr. Aruna Naik,

E-mail: sbapna.1@gmail.com

Copyright: (C) the author(s), publisher and licensee Medip Academy. This is an open-access article distributed under the terms of the Creative Commons Attribution Non-Commercial License, which permits unrestricted non-commercial use, distribution, and reproduction in any medium, provided the original work is properly cited.

\section{ABSTRACT}

Background: Hypertension is one of the common complications in pregnancy and contributes significantly to maternal and perinatal morbidity and mortality. The aim of the present study was to study placental grading by grading by ultrasonography in pregnancy complicated with hypertension and normotensive gravidas. To compare the foetal outcome regarding placental grading and its correlation pattern of placental grade distribution, type of delivery, foetal distress, birth asphyxia, foetal maturity, perinatal morbidity and mortality.

Methods: The present study was conducted for a period of 12 months, which included 200 patients who attended OPD at PDRMC, Udaipur. Inclusion criteria was hypertensive pregnant women with BP >140/90 $\mathrm{mmHg}$. Exclusion criteria was Pregnancy associated with other medical disorders, twin gestation, renal and cardiovascular disease and diabetes mellitus.

Results: 100 pregnant women with preeclampsia as study group. The most common age group in study group is $22-23$ Years. The grade III placenta was found early third trimester in study group. Caesarean delivery was more common mode of delivery in grade III placenta. In foetal outcome small for gestational age was more among the grade III placenta. Foetal distress, birth asphyxia, perinatal mortality, morbidity more among the grade III placenta among the study group.

Conclusions: Foetal complications were significantly more in study group compared to control group. Ultrasound placental grade III was statistically significant in correlating with foetal complications like foetal distress, birth asphyxia, perinatal morbidity and mortality.

Keywords: Ultrasonic placental grading, Third trimester, Hypertensive disorders, Foetal distress

\section{INTRODUCTION}

Hypertension is one of the common complications in pregnancy and contributes significantly to maternal and perinatal morbidity and mortality. The identification of this entity and effective management plays a significant role in the outcome of pregnancy both for the mother and the baby.

Placenta is an important foetal organ which is an intermediate link between the foetus and the mother. The foetus and placenta together called as foeto placental unit. Proper functioning of the placenta, growth changes, maturational changes is a must for the proper growth and development of the foetus in utero. ${ }^{1}$ The general role of placenta in maintenance of pregnancy is well understood but in recent years research has trended to concentrate on certain special aspects of its function.

The relationship between placental morphology function and foetal outcome has been the subject of study for many years. $^{2}$ 
Various complications in pregnancy have been correlated with specific micro and macroscopic placental changes.

With advances in ultrasound technology placenta can now be visualized in situ. ${ }^{3}$ Morphological changes can now be documented as pregnancy advances. With grey scale ultrasonography it is possible to identify changes in placental anatomy which formally have been recognized only by examination of the placenta after delivery. ${ }^{4}$

By serial ultrasound examination these changes can be detected as they occur since placenta is a foetal organ it seems logical that, it should mature in a fashion similar to that of other foetal organ system.

In order to categorise the phases of maturation of placenta, Grannum and associates Classified Ultrasonic Variations in placental appearance occurring during gestation and then to correlate these findings with an index of foetel lung maturity, the lecithin/spingomyelin ratio. ${ }^{4}$

The advent of antenatal detection of foetal pulmonary maturity by measurement of L/S ratio in amniotic fluid has resulted in a significant reduction in both perinatal morbidity and mortality. Unfortunately, this test requires the invasive procedure of amniocentesis, with its associated complication in some high-risk pregnancies where it as important to establish foetal maturity amniocentesis is often difficult or hazardous.

Ultrasonography provides a non-invasive technique for the evaluation of foetal gestational maturity. In 1979, Grannum et al4 described a method of classifying and grading placental maturity as the pregnancy advances based on ultrasound evaluation of placental textural changes in the in vivo placenta. The authors demonstrated a good correlation between maturational changes in the placenta as seen by ultrasound and the foetal pulmonary maturity as determined by L/S ratio. Petrucha and associates confirmed Grannum and associates findings and reported $100 \%$ correlation between $\mathrm{L} / \mathrm{S}$ ratio and grade III placenta whereas Quinlan and Crus reported 3 cases of grade III placenta with immature L/S ratio. ${ }^{5,6}$ In view of the above, the present study was undertaken to study the ultrasound placental grading in pregnancy complicated with hypertension and its correlation with foetal outcome.

\section{Incidence}

Incidence of PIH in the world varies in developing countries and the developed countries, from around $7 \%$ in Zimbabwe to around $0.81 \%$ in Colombia. ${ }^{7}$

Incidence of PIH in India ranges from 5-15\%, incidence being more in primigravida around $16 \%$, than in multigravida around $7 \%$. Upadhyay reported an incidence of $10 \%$ in rural India. ${ }^{7}$

\section{Aims and objectives}

To study placental grading by ultrasonography in pregnancy complicated with hypertension and normotensive gravidas.

To compare the foetal outcome regarding placental grading and it's correlation with the following: pattern of placental grade distribution, type of delivery, birth asphyxia, foetal maturity, perinatal morbidity and mortality.

\section{METHODS}

The data for the study was collected from 200 patients attending the department of OBG in Pannadhay Rajakiya Mahila Chikitsalaya (PDRMC) Ravindranath Tagore Medical College, Udaipur over the period of 12 months from January 2019 to December 2019.

\section{Inclusion criteria}

\section{For control group}

Pregnant women in third trimester, Blood pressure $<140 / 90 \mathrm{mmHg}$, no medical disorders like diabetes, renal disease, hypertension, singleton pregnancy and vertex presentation were included.

\section{For study group}

Pregnant women in third trimester, BP >140/90 mmHg, Singleton pregnancy and vertex presentation were included.

\section{Exclusion criteria}

Women with diabetes mellitus, hypertension, cardiovascular diseases, pregnancy associated with other medical disorders and twins were excluded.

\section{Methodology}

200 pregnant women in their third trimester of pregnancy were included for the study. It included 100 pregnant women with preeclampsia as study group and 100 normotensive pregnant women as control group. Detailed history was taken and general physical and obstetric examination was done. Ultrasonic placental grading was noted in both control and study group and the outcome of the study was studied in terms of placental grading, fetal distress, birth asphyxia, type of delivery, fetal maturity, perinatal morbidity and mortality.

\section{Statistical analysis}

The statistical analysis was done using Statistical package for social sciences (SPSS) 20.0. The results for each parameter (numbers and percentages) for discrete data and averaged (mean + standard deviation) for continuous data are presented in Table and Figure. Proportions were 
compared using Chi-square test and parametric data was analysed using student's 't' test.

\section{RESULTS}

Majority of patients were in 20-25yrs age group (49.5\%) with mean age 26.39 years in Control group and 26.18 years in study group.

Grade III changes in $<37$ weeks and >than 37 weeks of gestation between study and control group was statistically significant. $(\mathrm{p}<0.05)$

Spontaneous delivery was more in control group (54\%) compared to study group $(6 \%)$. Induced delivery and caesarean section were more in study group compared to control group. Induced delivery was $21 \%$ in control group compared to $31 \%$ in study group. Caesarean section was more in study group (63\%) compared to control group $(35 \%)$.

It was observed that with Grade III placenta, caesarean section rate was $51 \%$ in study group and $23 \%$ in control group which was statistically significant. $(\mathrm{p}>0.05)$

Women with Grade III placenta showed statistically significant difference between study $(25 \%)$ and control group $(14 \%)(\mathrm{p}<0.05)$.

Birth asphyxia is clinically defined as failure to initiate and maintain spontaneous respiration following birth or impaired or absent exchange of oxygen and carbon-dioxide combined with hypercapnea and hypoxia or anoxia.

Table 1: Mean age distribution among the study and control group.

\begin{tabular}{|llllllll|} 
& N & Mean age & SD & Minimum & Maximum & SEd value & P value \\
\cline { 1 - 5 } Control & 100 & 26.35 & 4.95 & 18 & 40 & \multirow{2}{*}{0.713} & 0.747 \\
\cline { 1 - 6 } & 100 & 26.12 & 5.12 & 18 & 40 & & \\
\hline
\end{tabular}

Table 2: Distribution of placental grade and type of delivery.

\begin{tabular}{|c|c|c|c|c|c|c|c|c|c|}
\hline \multirow[b]{3}{*}{ Group } & \multicolumn{9}{|c|}{ Placental grading } \\
\hline & \multicolumn{3}{|c|}{ Grade 1} & \multicolumn{3}{|l|}{ Grade 2} & \multicolumn{3}{|c|}{ Grade 3} \\
\hline & 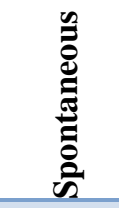 & 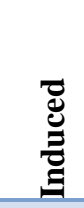 & 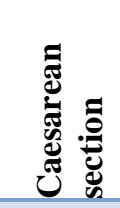 & 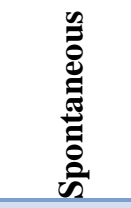 & 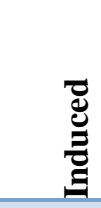 & 䄈 & 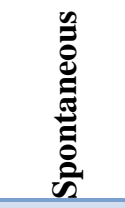 & 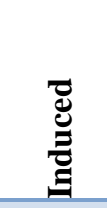 & 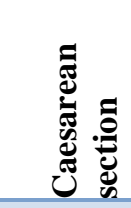 \\
\hline \multirow{2}{*}{ Control } & 0 & 0 & 0 & 24 & 3 & 12 & 20 & 18 & 23 \\
\hline & $0 \%$ & $0 \%$ & $0 \%$ & $24 \%$ & $3 \%$ & $12 \%$ & $20 \%$ & $18 \%$ & $23 \%$ \\
\hline \multirow{2}{*}{ Study } & 0 & 0 & 0 & 3 & 6 & 12 & 3 & 25 & 51 \\
\hline & $0 \%$ & $0 \%$ & $0 \%$ & $3 \%$ & $6 \%$ & $12 \%$ & $\%$ & $25 \%$ & $51 \%$ \\
\hline \multirow{2}{*}{ Total } & 0 & 0 & 0 & 27 & 9 & 24 & 23 & 43 & 74 \\
\hline & $0 \%$ & $0 \%$ & $0 \%$ & $18.5 \%$ & $4.5 \%$ & $12 \%$ & $11.5 \%$ & $21.5 \%$ & $32 \%$ \\
\hline$P$ value & & & & 0.865 & & & 0.905 & & \\
\hline
\end{tabular}

Table 3: Distribution of placental grade and Foetal growth.

\begin{tabular}{|c|c|c|c|c|c|c|}
\hline \multirow{3}{*}{ Group } & \multicolumn{6}{|c|}{ Placental grading } \\
\hline & \multicolumn{2}{|c|}{ Grade 1} & \multicolumn{2}{|c|}{ Grade 2} & \multicolumn{2}{|c|}{ Grade 3} \\
\hline & SGA & AGA & SGA & AGA & SGA & AGA \\
\hline \multirow{2}{*}{ Control } & 0 & 0 & 22 & 17 & 14 & 47 \\
\hline & $0 \%$ & $0 \%$ & $22 \%$ & $17 \%$ & $14 \%$ & $47 \%$ \\
\hline \multirow{2}{*}{ Study } & 0 & 0 & 10 & 11 & 25 & 54 \\
\hline & $0 \%$ & $0 \%$ & $10 \%$ & $11 \%$ & $25 \%$ & $54 \%$ \\
\hline \multirow{2}{*}{ Total } & 0 & 0 & 32 & 28 & 39 & 101 \\
\hline & $0 \%$ & $0 \%$ & $16 \%$ & $14 \%$ & $19.5 \%$ & $50.5 \%$ \\
\hline$P$ value & - & & 0.515 & & 0.255 & \\
\hline
\end{tabular}


Table 4: Distribution of placental grade and birth asphyxia.

\begin{tabular}{|c|c|c|c|c|c|c|}
\hline \multirow{3}{*}{ Group } & \multicolumn{6}{|c|}{ Placental grading } \\
\hline & \multicolumn{2}{|c|}{ Grade 1} & \multicolumn{2}{|l|}{ Grade 2} & \multicolumn{2}{|l|}{ Grade 3} \\
\hline & Present & Absent & Present & Absent & Present & Absent \\
\hline \multirow{2}{*}{ Control } & 0 & 0 & 20 & 19 & 9 & 52 \\
\hline & $0 \%$ & $0 \%$ & $20 \%$ & $19 \%$ & $9 \%$ & $52 \%$ \\
\hline \multirow{2}{*}{ Study } & 0 & 0 & 11 & 10 & 18 & 61 \\
\hline & $0 \%$ & $0 \%$ & $11 \%$ & $10 \%$ & $18 \%$ & $61 \%$ \\
\hline \multirow{2}{*}{ Total } & 0 & 0 & 31 & 29 & 27 & 113 \\
\hline & $0 \%$ & $0 \%$ & $15.5 \%$ & $14.5 \%$ & $13.5 \%$ & $56.5 \%$ \\
\hline$P$ value & - & & 0.935 & & 0.232 & \\
\hline
\end{tabular}

Table 5: Distribution of placental grade and perinatal morbidity.

\begin{tabular}{|c|c|c|c|c|c|c|}
\hline \multirow{3}{*}{ Group } & \multicolumn{6}{|c|}{ Placental grading } \\
\hline & \multicolumn{2}{|l|}{ Grade 1} & \multicolumn{2}{|l|}{ Grade 2} & \multicolumn{2}{|l|}{ Grade 3} \\
\hline & Present & Absent & Present & Absent & Present & Absent \\
\hline \multirow{2}{*}{ Control } & 0 & 0 & 17 & 22 & 5 & 56 \\
\hline & $0 \%$ & $0 \%$ & $17 \%$ & $22 \%$ & $5 \%$ & $56 \%$ \\
\hline \multirow{2}{*}{ Study } & 0 & 0 & 10 & 11 & 12 & 67 \\
\hline & $0 \%$ & $0 \%$ & $10 \%$ & $11 \%$ & $12 \%$ & $67 \%$ \\
\hline \multirow{2}{*}{ Total } & 0 & 0 & 27 & 33 & 17 & 123 \\
\hline & $0 \%$ & $0 \%$ & $13.5 \%$ & $16.5 \%$ & $8.5 \%$ & $61.5 \% \%$ \\
\hline$P$ value & - & & 0.765 & & 0.209 & \\
\hline
\end{tabular}

Table 6: Distribution of placental grade and perinatal mortality.

\begin{tabular}{|lllllll|}
\hline \multirow{2}{*}{ Group } & \multicolumn{2}{l}{ Placental grading } & Grade 2 & & Grade 3 \\
& Grade 1 & \multicolumn{1}{l}{ Absent } & Present & Absent & Present & Absent \\
\hline \multirow{2}{*}{ Control } & 0 & 0 & 14 & 25 & 10 & 51 \\
& $0 \%$ & $0 \%$ & $14 \%$ & $25 \%$ & $10 \%$ & $51 \%$ \\
\hline \multirow{2}{*}{ Study } & 0 & 0 & 11 & 10 & 18 & 61 \\
\hline \multirow{2}{*}{ Total } & $0 \%$ & $0 \%$ & $11 \%$ & $10 \%$ & $18 \%$ & $61 \%$ \\
\hline P value & 0 & 0 & 25 & 35 & 28 & 112 \\
\hline
\end{tabular}

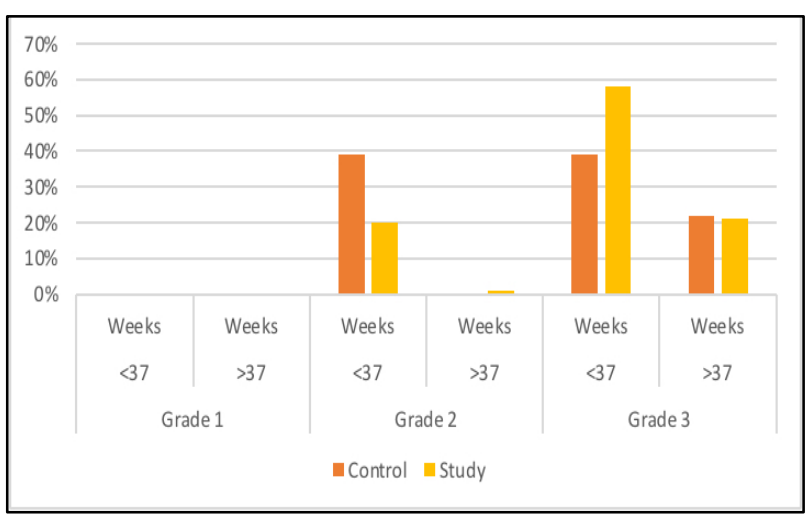

Figure 1: Distribution of placental grading and ultrasound gestational age in weeks.
Birth asphyxia was observed only in grade II and III placental grades. In study group birth asphyxia was equal (29\%) to control group. Birth asphyxia was more with grade II placenta in control group (20\%) compared to study group $(11 \%)$ but which was not statistically significant $(\mathrm{p}>0.05)$.

Perinatal morbidity was considered by the presence of any of the following during the stay in the hospital (approximately within 7 days: a) Infection b) Birth injuries c) Aspiration pneumonia d) Jaundice

Perinatal morbidity in study group (22\%) was same as compared to control group which was not statistically significant $(\mathrm{p}>0.05)$. 
Perinatal morbidity was more in study group in grade III placenta (12\%) compared to control group (5\%) and which was statistically not significant $(\mathrm{p}>0.05)$.

Perinatal mortality is death of fetus/ baby after the period of viability and before or during delivery or within the first 7 days of delivery. The perinatal mortality was observed in study group, $11 \%$ with grade 2 and $18 \%$ with grade III. Perinatal mortality was more in study group (28\%) compared to control group (24\%) and perinatal mortality in study group with Grade 3 placenta (18\%) compared to control group (10\%). There was no statistically significant difference observed between study and control group $(\mathrm{p}>0.05)$.

\section{DISCUSSION}

100 pregnant women with pregnancy induced hypertension as study group and 100 normotensive pregnant women as control group admitted PDMH, Udaipur, Rajasthan were taken for study. Both Control and study groups clinically examined, inclusion and exclusion criteria were fulfilled. The ultrasonic placental grading was correlated with foetal outcome. It is believed that the placenta matures through the various grades during pregnancy and the maturation changes progress sequentially to a higher grade but may remain the same until term and in abnormal pregnancy the placenta may mature more rapidly through the various grades of placental maturation.

Table 7: Placental grade distribution.

\begin{tabular}{|lllll|}
\hline & $\begin{array}{l}\text { Grade } \\
\text { 0 }\end{array}$ & $\begin{array}{l}\text { Grade } \\
\text { I }\end{array}$ & Grade II & $\begin{array}{l}\text { Grade } \\
\text { III }\end{array}$ \\
\hline $\begin{array}{l}\text { Present } \\
\text { study }\end{array}$ & $0 \%$ & 0 & $21 \%$ & $79 \%$ \\
\hline $\begin{array}{l}\text { Petrucha } \\
\text { (1982) }^{\mathbf{5}}\end{array}$ & $4 \%$ & $48 \%$ & $33 \%$ & $15 \%$ \\
\hline $\begin{array}{l}\text { Mishra N } \\
\text { (2006) }^{\mathbf{8}}\end{array}$ & $0 \%$ & $15 \%$ & $58 \%$ & $27 \%$ \\
\hline $\begin{array}{l}\text { Sunanda } \\
\text { (2014) }^{\mathbf{9}}\end{array}$ & $33 \%$ & $24 \%$ & $22.4 \%$ & $17.8 \%$ \\
\hline
\end{tabular}

1 placenta is not observed in the present study.

In the control group $39 \%$ and $61 \%$ women had placental grades II and III respectively as against $21 \%$ and $79 \%$ respectively of the study group women and it was found to be statistically not significant $(p>0.05)$ compared to above studies. $^{5,8,9}$

Grade III placental changes were shown to precede PIH by 1-6 weeks. Present study showed grade III placental changes in $58 \%$ with PIH cases in less than 37 weeks of gestation compared to Mishra study (35\%), Caroll et al $(22.7 \%)$ and Sunanda. ${ }^{8-10}(23 \%)$.
In the present study grade III placental changes below 37 weeks of gestation and above 37 weeks of gestation between study and control group was statistically significant.

Spontaneous delivery rate was more in the control group (44\%) and study group (6\%). Labour was induced in $31 \%$ of the cases in study group compared to $21 \%$ in control group.

Labour induction was required more frequently in cases of uncontrolled maternal hypertension in order to prevent maternal and foetal complications.

The present study showed caesarean section rate was $63 \%$ in study group compared to $35 \%$ in the control group and it was found that there is a statistically significant difference between study and control group with respect to LSCS rate. $(p<0.05)$ Caesarean section rate with grade III placenta in study group was more $(51 \%)$ compared to control group (23\%) which is statistically significant. Caesarean section was done in most of the cases for foetal distress, failed induction, PROM, CPD and nonreactive NST. Pre-term delivery rate was significantly more in study group compared to control group

In the present study IUGR babies were observed in $10 \%$ with grade II, $25 \%$ with grade III in the study group and IUGR babies were significantly more with grade III placental in study group (25\%) compared to control group (14\%). Patterson et al (1983) observed higher incidence of SGA babies with grade III placenta. Same observations were made by Caroll and Sunanda et al..$^{9-11}$

It was believed that in hypertensive disorders of pregnancy, the accelerated placental maturation results in chronic intra uterine stressful situation which in turn leads to hampered fetal growth and finding of grade III placenta before 37 weeks which require close fetal monitoring to detect abnormal fetal growth or fetal distress.

The present study showed statistically significant difference in foetal growth between control and study group in all the placental grading and more IUGR cases were observed in the study group (25\%) compared to control group $(14 \%)$ with Grade III placenta $(\mathrm{p}<0.05)$. Sunanda et al observed $50 \%$ incidence of fetal distress with grade III placenta in PIH patients. ${ }^{9}$ Mishra study showed fetal distress more in study group (26\%) compared to $11 \%$ in control group and with grade III placenta fetal distress was observed in $40.43 \%$ in study group compared to $7.41 \%$ in control group. ${ }^{8}$

The present study shows fetal distress $40 \%$ in study group compared to $27 \%$ in control group which is statistically significant $(\mathrm{p}>0.05)$ and with grade III placenta foetal distress incidence was found to be statistically not significant $(28 \%)$ in study group compared to $14 \%$ in control group). 
In the present study perinatal morbidity with grade III placenta was more (12\%) compared to $5 \%$ in control group which is statistically significant.

Mishra's study showed in study group with grade III placenta (9\%) compared to $1 \%$ in control group. ${ }^{8}$ Similar higher incidence was observed by Hill and Brekle and Sunanda et al..$^{9,12}$

There was a statistically significant difference in parental mortality observed between study group (29\%) and control group $(24 \%)(\mathrm{p}<0.05)$. Hypertension is associated with placental infarct with reduced placental growth. These pathological lesions of placenta result in decreased placental perfusion and thereby leading to fetal growth restriction and fetal hypoxia. Perinatal mortality correlated with various reports that PIH is associated with increased perinatal loss.

The present study showed higher perinatal mortality rate with grade III placenta in study group $18 \%$ compared to $10 \%$ in control group which is statistically significant.

Patterson and associates 11 noted that early placental senescence in PIH with IUGR (16.7\%) compared to $4 \%$ in control group.

Kazzi et al have demonstrated an increased incidence of growth restriction with grade III placenta $(59 \%)$ and $78 \%$ incidence of perinatal problems (growth restriction-fetal demise) when grade III placenta was identified before term. ${ }^{13}$

Above findings noted above strongly suggest that the foetal complications were more in pregnancy induced hypertension when compared to normotensive pregnant women.

\section{CONCLUSION}

Foetal complications were significantly more in study group compared to control group. Ultrasound placental grade III was statistically significant in correlating with foetal complications like foetal distress, birth asphyxia, perinatal morbidity and mortality. There was no statistically significant correlation between ultrasound placental grading and foetal outcome.

Funding: No funding sources Conflict of interest: None declared
Ethical approval: The study was approved by the Institutional Ethics Committee

\section{REFERENCES}

1. Winsberg F. Echographic changes with placental ageing. J. Cli. Ultrasound. 1973;1:52.

2. Fisher CC, Garret W, Kosoff G. Placental ageing monitored by Gray - scale echography. Am. J Obstet. 1975;124:143.

3. Fisher CC, Garret W, Kosoff G. Placental ageing monitored by Gray -scale echography. Am. J Obstet. 1976;124:143.

4. Grannum PA, Bekowits RL, Hobbins JC. The Ultrasonic changes in the maturing placenta and their relation to foetal pulmonic maturity. Am J Obstet Gynecol. 1979;133:915.

5. Petrucha RA, Colde SH, Platt LD. Real Time ultrasound of the placenta in assessment of foetal pulmonic maturity. Am J Obstet Gynecol. 1982;142:463.

6. Quinlan RW, Crus AC. Ultrasonic placental grading and foetal pulmonary maturity. Am J Obstet Gynecol. $1982 ; 142$.

7. Upadhyay M, Rao ST. Hypertensive disorders in pregnancy. Indian J Anesthesia. 2018;62:675-85.

8. Mishra N. Clinical significance of placental grading by ultrasound in hypertensive disorders of pregnancy and its correlation with foetal outcome. JDMS. 2006;6:5.

9. Sunanda KM, Srinivas K, Satyanarayana. Clinical Significance of Ultrasonic Placental Grading during Third Trimester in Hypertensive Disorders of Pregnancy and its Correlation with Fetal Outcome. Journal of Evidence Based Medicine and Healthcare. 2014;1(7):599-607.

10. Carrol B. Ultrasonic features of preeclampsia. J Clin Ultrasound. 1980;8:483.

11. Patterson RM, Hayashi RH, Dora Cavazos LVN. Ultrasonographically observed early placental maturation and perinatal outcome. Am J Obstet Gynecol. 1983;147-773.

12. Hill LM, Breckle R. The relationship of placental grade by USG to markers of fetal lung maturity; Radiology. 2004; 148;805-1983.

13. Kazzi GM, Gross TL, Sokol RJ, Kazzi NJ. Detection of IUGR. A new use for sonographic placental grading. Am J Obstet Gynecol. 1983;143:733.

Cite this article as: Naik A, Khoiwal S, Sharma N, Aarthy P. Clinical significance of ultrasonic placental grading during third trimester in hypertensive disorders in pregnancy and its correlation with fetal outcome in tertiary care centre. Int J Reprod Contracept Obstet Gynecol 2021;10:3325-30. 